\title{
A nação em jogo: esporte e guerra colonial na Guiné Portuguesa (1961-1974).
}

\author{
The nation at stake: sport and colonial war in Portuguese Guinea \\ (1961-1974).
}

Victor Andrade Melo 1

\section{RESUMO}

Este artigo tem por objetivo discutir as tensões que cercaram a experiência esportiva na Guiné Portuguesa entre os anos de 1961, início da guerra colonial em Angola, e 1974, data de reconhecimento da independência da província por parte de Portugal. Sugere-se que o estudo permite lançar um olhar sobre os conflitos anticoloniais, bem como sobre os estertores do império português. Para alcance do objetivo foram majoritariamente utilizados periódicos publicados no período em tela, três deles editados por órgãos governamentais - o Boletim Geral do Ultramar, o Boletim Cultural da Guiné Portuguesa e o Notícias da Guiné, e um produzido pela Igreja Católica, o Arauto, que também recebia subsídios estatais.

Palavras-chave: História da África. História do Esporte. Colonialismo. Guiné. Guerra Colonial.

\section{ABSTRACT}

This article aims to discuss the tensions surrounding the sporting experience in Portuguese Guinea between 1961, the beginning of the colonial war in Angola, and 1974, year of recognition of the independence of Guinea. It is suggested that the study allows to cast a glance on anticolonial war as well as the end of the Portuguese empire experience. To reach the goal they were mainly used periodicals published during the period in question, three of them published by government agencies - o Boletim Geral do Ultramar, o Boletim Cultural da Guiné Portuguesa e o Notícias da Guiné, and other produced by the Catholic Church, o Arauto, that also received government subsidies.

Keyword: Africa History. Sport History. Colonialism. Guinea. Colonial War.

1 Professor da Universidade Federal do Rio de Janeiro, atua no Programa de Pós-Graduação em História Comparada/Instituto de História. 


\section{Introdução}

O ano de 1961 foi marcante na história de Portugal. As insatisfações com os rumos da nação, que já vinham se delineando há algum tempo, manifestaram-se em ações concretas de questionamento da longa ditadura salazarista. O fim do Estado Novo ${ }^{2}$ ainda tardaria mais de uma década, processo que esteve fortemente relacionado aos conflitos anticoloniais que coexistiram em Angola, Moçambique e Guiné.

Em fevereiro de 1961, em Angola eclodiu a guerra colonial. Em dezembro, Portugal sofreu uma primeira derrota. A União Indiana ocupou Goa, Damião e Diu. O governo metropolitano, a fim de reagir a essas ocorrências e ao aumento das pressões internacionais, ${ }^{3}$ se negando a promover mudanças profundas, tanto procurou ampliar sua presença nos territórios africanos, inclusive do ponto de vista policial e militar, quanto entabulou novo ajuste cosmético na sua política colonial, fortalecendo a argumentação de que não possuía colônias, mas sim províncias ultramarinas ${ }^{4}$ plenamente integradas ao país (PIMENTA, 2010). No decorrer da década:

Com a guerra colonial estendida a três frentes de batalha e sem solução militar expectável, do campo acadêmico e científico ligado ao estudo dos problemas ultramarinos [...[ surgiu a ideia de que o êxito da luta que se travava pela defesa do ultramar não passava apenas pelas armas, mas, antes e simultaneamente, pela promoção econômica e social de todos os grupos populacionais, com primazia para as etnias autóctones [...]. Esta visão alternativa, partilhada por acadêmicos e técnicos, só muito tardiamente seria acatada pelo poder político e militar (CASTELO, 2014, p. 528).

No âmbito esportivo das colônias, são perceptíveis desdobramentos dessas ações. Desde a década de 1950, o governo metropolitano entabulou algumas iniciativas relacionadas à prática: a instituição de Conselhos Provinciais de Educação Física, o estímulo à realização de jogos internacionais, o patrocínio de excursões de clubes da metrópole ao ultramar, o

2 O Estado Novo português(1926-1974) foi um regime autoritário, antipartidário e antiparlamentar. Nesse período, o país foi dirigido por Salazar (até 1968) e por Marcelo Caetano (até a 1974). Para mais informações, ver Pimenta (2010).

3 No pós $2^{\text {a }}$ Grande Guerra, Portugal sofreu duas grandes pressões internacionais: para mudar o regime considerado pouco democrático e para encaminhar o processo de descolonização. Vale considerar que o país somente foi aceito na ONU em 1955 (PIMENTA, 2010).

4 Desde 1951, Portugal já adotara a designação para se referir a seus territórios na África e Ásia. 
incentivo à presença de atletas e equipes africanas e asiáticas nos campeonatos na cionais, inclusive na Taça de Portugal (MELO; BITTENCOURT, 2013).

Impactos desse processo foram sentidos na Guiné. O governo português procurou aumentar sua intervenção no território, bem como encaminhar iniciativas de incrementar o desenvolvimento da província. Em linhas gerais, percebe-se que:

\begin{abstract}
Durante os 13 anos de guerra colonial houve uma melhoria das condições de vida das populações africanas, uma extensão da escolaridade e dos cuidados primários de saúde. Ainda assim, o bemestar era apanágio dos colonos brancos e a segurança um privilégio circunscrito aos grandes núcleos urbanos. Neste período, embora a esmagadora maioria dos africanos habitasse os meios rurais, devido ao progresso da industrialização, do assalariamento e da urbanização, deuse um êxodo assinalável em direção às periferias das principais cidades [...] (CASTELO, 2014, p. 520).
\end{abstract}

Na Guiné, do ponto de vista societário, o quadro se tornou significativamente mais complexo. Fortaleceu-se um estrato intermediário de africanos - cabo-verdianos e guineenses, inseridos numa esfera outrora somente reservada aos brancos e poucos "civilizados" (CARDOSO, 1992). Esse grupo começou a tomar mais consciência e ter mais condições de se posicionar frente ao cenário de opressão e desigualdade. Nesse âmbito surgiram as lideranças que desencadearam os movimentos de contestação e combate ao colonialismo português, cujo nome mais notável foi Amílcar Cabral, principal dirigente do Partido Africano pela Independência da Guiné e de Cabo Verde (PAIGC). 5

A guerra colonial na Guiné teve início em 1963. No decorrer da década, o conflito foi se acentuando, se espraiando e impactando o cotidiano da província, mais até do que em Angola e Moçambique. Nos anos 1970, os embates se acirraram. Tratou-se de uma luta cruel, que ceifou muitas vidas e consumiu elevados recursos, bastante tensa para ambos os lados, inclusive no que tange às tensões internas de cada um dos grupos envolvidos.

No âmbito do esporte se pode sentir o impacto dos conflitos. Melo (2014) informa que o desenvolvimento esportivo na Guiné foi tardio se comparado ao de outras colônias portuguesas. Ainda assim, graças a ação de Sarmento Rodrigues (governador entre os anos de 1945 e 1949), tornou-se o primeiro lugar do ultramar no qual a prática foi explicitamente

5 Há polêmicas sobre a data de fundação do PAIGC, sendo certo que se deu na transição das décadas de 1950 e 1960 . Para mais informações, ver Silva (2006). 
mobilizada pelo poder governamental, exemplo para experiências semelhantes em outras províncias desencadeadas.

O que inspirou tais ações, segundo o autor, foi a ligação de Sarmento Rodrigues com as ideias de Gilberto Freyre, antecipando o denotado uso do lusotropicalismo pelo governo metropolitano que se tornaria notável nos anos 1950 (CASTELO, 1998). O que terá ocorrido na década de 1960, com as mudanças ocasionadas pela guerra colonial?

Sugerindo-se que este estudo permite lançar um olhar sobre os conflitos coloniais, bem como sobre os estertores do império português, este artigo tem por objetivo discutir as tensões que cercaram a experiência esportiva da Guiné Portuguesa entre os anos de 1961, início dos embates independentistas em Angola, e 1974, data de reconhecimento da autonomia da província por parte de Portugal.

Para alcance do objetivo foram majoritariamente utilizados periódicos publicados no período em tela, três deles editados por órgãos governamentais - o Boletim Geral do Ultramar, o Boletim Cultural da Guiné Portuguesa e o Notícias da Guiné, e um produzido pela Igreja Católica, o Arauto, que também recebia subsídios estatais.

Centralmente estamos interessados nos discursos dos colonos e instâncias governamentais portuguesas. De toda forma, apesar de expressarem em grande medida a visão metropolitana, há uma importante diferença entre os periódicos. Os Boletins eram diretamente produzidos por agentes a serviço do Estado, de passagem pela província, enquanto os responsáveis pelos outros dois veículos eram jornalistas residentes fixos na Guiné. Nesses últimos, era mais usual encontrar críticas a alguns aspectos do cotidiano da colônia, sempre com o argumento de que se buscava, na verdade, contribuir para o seu progresso, jamais propugnando sua independência.

No decorrer do estudo, tivemos em conta o sugerido por Bale e Cronin (2003) no que tange às contribuições das formulações pós-coloniais para os estudos do esporte. 6 Entre outros enfoques, inferem os autores que devem ser melhor compreendidos os discursos formulados pelo colonizador acerca da prática esportiva, inclusive no que se refere a sua operacionalização para atender seus interesses. Não se trata, contudo, de afirmar que o colonizado apreendeu de forma homogênea e linear tais compreensões. Nesse estudo, todavia, não vamos nos debruçar sobre este aspecto. Interessa-nos mormente aquilo que diz respeito a possíveis entendimentos do fenômeno que atendiam a propostas de manutenção do jugo colonial.

Ao final, apresentamos um debate sobre a prática do esporte nas fileiras do PAIGC menos com o intuito de discutir uma possível linha de contestação, mais como forma de 
estabelecer uma breve comparação entre os diferentes usos e compreensões acerca do fenômeno, apontando possibilidades futuras de investigação.

\section{Enquanto não chegavam (definitivamente) os conflitos}

Até a meados dos anos 1960, no que tange à estruturação da prática esportiva, não se percebem profundas mudanças no quadro que se delineou no fim da década anterior. Desde 1957, com o Massacre do Pindjiguiti, ${ }^{7}$ tornara-se aparente a existência de grupos de contestação na Guiné. Todavia, ainda que já se sentisse algum impacto, os conflitos não eram de tal monta a ponto de definitivamente interferirem no cotidiano da província, inclusive no que tange ao esporte.

Entre novembro e maio, os eventos esportivos eram promovidos com frequência. Na época do "defeso", quando chegavam "as chuvas, as trovoadas e os tornados, [...], o mau tempo que assola a Guiné de ponta a ponta" (ARAUTO, 1961a, p. 3), se interrompia ou muito se reduzia a realização de torneios e campeonatos.

Os clubes, portanto, continuavam a se manter em atividade, enfrentando os mesmos problemas já delineados nos anos 1950 (dificuldade financeira, falta de continuidade de algumas ações, deficiências estruturais). Até mesmo por isso, a imprensa seguia criticando o baixo desenvolvimento do esporte, responsabilizando mais as agremiações do que o governo:

[...] queixam-se as associações de que cada vez é mais diminuta a assistência aos jogos que patrocinam e que as receitas não chegam sequer para fazer face às despesas mais indispensáveis. Mas como pode o público corresponder à chamada se são as próprias entidades desportivas as primeiras a não corresponderem aos desejos do público? (ARAUTO, 1961b, p. 4).

Como no período anterior, era flagrante a dependência de incentivo estatal, que concedia subsídios às iniciativas esportivas dependendo não só dos recursos disponíveis como também da sensibilidade dos administradores.

7 Sobre a relevância do massacre no que tange à organização de movimentos de contestação, ver Silva (2006). 
Citemos dois exemplos. Persistiu sempre o desejo de iluminar o campo de futebol do Estádio Sarmento Rodrigues, intuito dificultado pelos próprios limites da rede elétrica de Bissau. A única saída seria comprar um gerador próprio, o que não chegou a ser feito. De outro lado, em 1966, se inaugurou com grande festa uma piscina na capital, na Associação Comercial, Industrial e Agrícola da Guiné. Para tal, o governo contribuiu substancialmente com recursos, como o fizera antes em outras cidades (como em Farim, por exemplo).

Seguiram também constantes as críticas à baixa qualidade técnica dos jogos e à falta de investimento no preparo físico de atletas e da população. Um cronista contestou, inclusive, o fato de o Liceu Honório Barreto, inaugurado em 1957, não possuir um espaço adequado para a prática de esportes (ARAUTO, 1961c, p. 3). O reitor em exercício, Antonio Caldeira Firmino, respondeu ter clareza da importância da educação física, estando prevista para breve a construção de um ginásio e contratação de professores especialista s (ARAUTO, 1961d, p. 3).

De toda forma, parece possível afirmar que entre os mais jovens aumentou a prática de esportes, inclusive entre as mulheres. Uma das responsáveis por isso foi a Mocidade Portuguesa, que, assim como ocorrera em outras províncias, ampliou sua atuação na Guiné. ${ }^{8}$

A entidade passou a atuar com os mais distintos grupos sociais. Para além do envolvimento de nativos nas atividades da Mocidade Portuguesa, vale destacar a constante inserção de apresentações de danças "indígenas" nos seus eventos. Claramente tratava-se de uma certa valorização do local, atitude encarada como sinal da suposta peculiaridade da colonização portuguesa, que sem abandonar a missão civilizatória, denotava respeito pelas coisas da terra.

Figura 1 - Grupo folclórico dos Bijagos em evento da Mocidade Portuguesa

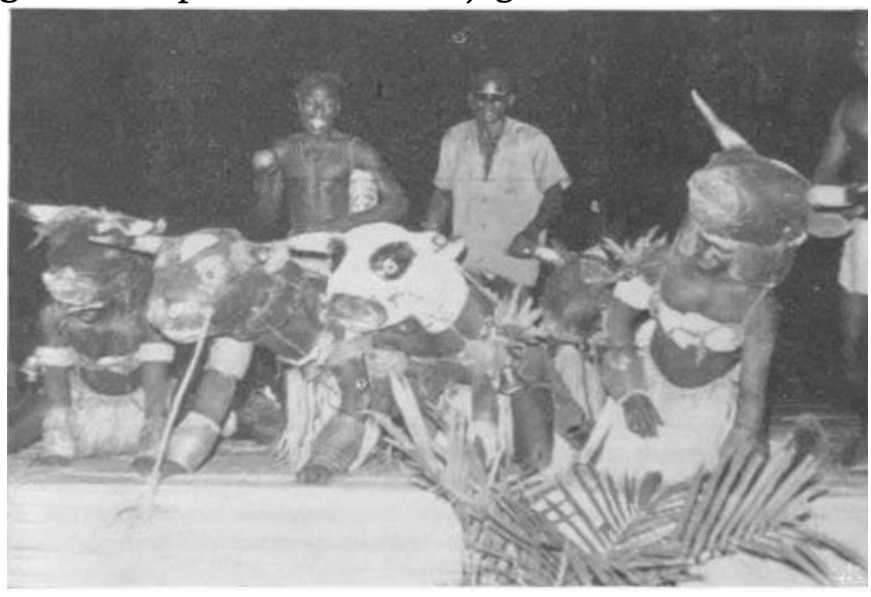

Exibição do grupo folclórico bijagó no encerramento das actividades da Mocidade Portuguesa

Fonte: Boletim Cultural da Guiné Portuguesa (1962, p. 485).

8 Para mais informações sobre a Mocidade Portuguesa, ver Pimentel (2007) e Vieira (2008). 
Essa foi mais uma das estratégias adotadas pelo governo metropolitano para, fazendo frente às pressões internacionais, manter o estatuto colonial. Para Cardoso (1992), como em outras províncias, na Guiné tratou-se claramente de uma ideologia racial, escamoteada por iniciativas assimiliacionistas e integracionistas. Era claro o caráter racializado e hierárquico do regime português.

Enfim, a despeito dos limites e ainda que de maneira irregular, percebe-se na província boa movimentação esportiva, a promoção, em várias cidades, de eventos de diversas modalidades (especialmente futebol, voleibol, basquetebol, hóquei e tênis). Os campeonatos e torneios tornaram-se até mesmo melhor estruturados, sempre contando com a presença de autoridades que buscavam aproveitar a popularidade da prática para representar os interesses metropolitanos. Majoritariamente, colonos e funcionários governamentais integravam as equipes, mas já se identifica alguma presença de africanos, notadamente de cabo-verdianos. Os nativos encontravam muitas restrições no que tange a seu envolvimento com as iniciativas das agremiações.

É interessante perceber que outras atividades de entretenimento também se dinamizaram na primeira metade da década de 1960, inclusive para atender a maior presença de metropolitanos, especialmente militares. Apresentações musicais, teatrais e de filmes - notadamente no cinema da UDIB e do Sporting Clube de Bafatá, tornaram-se mais constantes. Ampliou-se o número de bares, restaurantes e lanchonetes. Mais excursões turísticas foram oferecidas, pelo menos até o momento em que o espraiamento dos conflitos armados interferiu nas condições de trânsito pela província, como o fez nos mais diversos aspectos do cotidiano, inclusive no âmbito esportivo.

\section{Conflitos em campo}

De diferentes maneiras, os conflitos interferiram na dinâmica esportiva. Um dos aspectos notáveis foi o aumento da influência e presença de membros das forças armadas. ${ }^{9}$ Vejamos que, em 1961, quando informou-se que as participações de militares nas competições foram temporariamente suspensas (ARAUTO, 1961e, p. 2), para não os desviar de suas funções, tendo em vista o início da guerra colonial em Angola, os cronistas muito lamentaram a decisão por considerar que eram personagens importantes para o

9A forças armadas portuguesas chegaram a contar com mais de 36.000 homens na província (WOOLLACOTT, 1983). Se tivermos em conta que a população não chegava a 500.000, podemos perspectivar a importância da presença dos militares. 
desenvolvimento do esporte local. Assim observou o presidente da União Desportiva e Internacional de Bissau (UDIB), ${ }^{10}$ Joaquim Rocha:

[...] não somente no futebol, mas em todas as outras modalidades, os rapazes militares que para o bem da nação ora se encontram na nossa Província da Guiné deixarão não o sangue mas um valor técnico trazido da metrópole e que os nossos rapazes assimilarão com facilidade para o progresso do desporto guineense (ARAUTO, 1961f, p. 3).

Em várias ocasiões, em diversas modalidades, ainda mais no futebol, a participação de militares foi saudada. Alguns foram mesmo muito celebrados por sua habilidade técnica. Em geral, já tinham uma trajetória na metrópole e, ao cumprirem o serviço obrigatório na Guiné, jogavam nos clubes locais até retornarem ao Portugal europeu. Os cronistas destacavam que sua presença tinha uma dupla contribuição, para a defesa da província contra as investidas dos "terroristas" e para o incremento do esporte guineense.

Equipes das forças armadas também participaram de eventos esportivos. Em 1967, o Torneio de Páscoa contou com a presença da seleção nacional de militares, saudada por um cronista como uma forma de exaltação do império:

Foi este o último elo que ligou os desportistas da Guiné e mãe Pátria, nesta magnifica jornada, tão preciosa e necessária ao fomento de outros empreendimentos do gênero [...] que jamais se poderá apagar da mente deste povo modesto, mas cheio de tradições e grande, enorme, magnânimo, na arte de receber. Bem hajam, valentes soldados de Portugal, que a este cantinho trouxeram um pouco da recordação do nosso verdadeiro Lar. Obrigado, rapazes! (ARAUTO, 1967a, p. 6).

Dando sequência ao que ocorrera na década anterior, mobilizava-se o esporte para atender os interesses do governo português. Os meios de comunicação, ao mesmo tempo que davam voz a tais intuitos, tentavam dar uma impressão de normalidade, mesmo quando foram se acirrando os conflitos.

10 A UDIB era o mais antigo clube da província, majoritariamente formado por brancos colonos da elite. Os posicionamentos de suas diretorias estiveram constantemente alinhados aos interesses metropolitanos, a despeito das constantes críticas à falta de mais investimentos governamentais no esporte. 
Militares também ocuparam funções importantes nas direções de entidades ligadas ao esporte, como foi o caso do capitão Antonio Rodrigues Rebelo de Carvalho, que, em 1963, assumiu o Conselho Provincial de Educação Física, sendo empossado diretamente pelo governador, que assim "procurou dar relevo para assinalar o profundo interesse do governo pela atividade desportiva" (ARAUTO, 1963a, p. 2). Na ocasião, se prometeu a construção de mais instalações para todas as modalidades, o investimento no aperfeiçoamento de treinadores e árbitros, a manutenção de apoio a clubes e promoção de torneios, bem como reformas no Estádio Sarmento Rodrigues.

Nesse mesmo ano de 1963, uma novidade trouxe novas expectativas para os adeptos do esporte na Guiné, a implantação do Totobola.11 Para um cronista, era importante ressaltar que o apostador não estaria só "tentando a sua sorte [...] como também prestando alto e valioso contributo ao desporto nacional e ao campo social - desenvolvimento e revigoramento físico da mocidade e recuperação daqueles cuja adversidade atingiu" (ARAUTO, 1963b, p. 3).

As expectativas não se cumpriram. Com o espraiamento dos conflitos, em alguns lugares ficou difícil promover jogos. Alguns atletas, árbitros e dirigentes chegaram a morrer em decorrência da guerra. Quando isso ocorria, os clubes faziam algo para ajudar financeiramente a família, como organizar partidas com renda destinada à causa. Um cronista bem sugeriu o que motivava tais ações: "A Guiné, que ao desporto sempre tem dedicado especial atenção, não pode ficar inativa a tão dramático acontecimento" (ARAUTO, 1967b, p. 2). A todo momento, as direções das agremiações demonstravam sua vinculação aos interesses da metrópole.

Alguns anos antes, com o início dos conflitos em Angola, já tinham se desencadeado algumas iniciativas semelhantes entre os esportistas guineenses. Jogos de futebol foram organizados para angariar recursos ou donativos a serem enviados para a província do Sul. Nessas ocasiões, conclamou-se o público a demonstrar a solidariedade para com a nação, com a integridade do império. Posteriormente, celebrou-se o bom resultado:

Os desportistas e de uma maneira geral toda a população da cidade e um grande número que se deslocou do interior da Província gritaram bem alto o seu "presente", associando-se à nossa jornada de solidariedade para com as inocentes vítimas do terrorismo da portuguesíssima Província de Angola (ARAUTO, 1961g, p. 3).

11 As Apostas Mútuas Desportivas, mais conhecidas como Totobola, eram uma loteria administrada pela Santa Casa de Misericórdia em que parte da arrecadação se destinava ao desenvolvimento esportivo. 
Houve, todavia, uma ocorrência divergente que comprometeu as equipes. Muitos jogadores cabo-verdianos e guineenses foram mobilizados pelas lideranças do PAIGC para participar das lutas anticoloniais. Importantes comandantes do Partido, futuros dirigentes da Guiné independente, foram futebolistas, como Nino Vieira, Aristides Pereira, Bobo Keita, Constantino Teixeira. O próprio Amílcar Cabral, que sempre tivera muita ligação com o esporte, inaugurou essa linha de ação de conscientização por meio de contatos na esfera esportiva.12

O maior impacto do espraiamento dos conflitos se sentiu na realização de eventos internacionais. No primeiro semestre de 1961, anunciou-se o adiamento dos Jogos Desportivos do Mundo Português, ideia acalentada por muito tempo, com o intuito de celebrar a união da nação por meio do esporte (MELO, 2016). Tal decisão deveu-se aos acontecimentos em Angola, "que destroçaram lares portugueses e encheram de luto a nação", interferindo na "própria deslocação dos atletas das várias províncias ultramarinas", "dificultada na medida em que ali estão naturalmente empenhadas todas as disponibilidades de nossa frota aérea" (ARAUTO, 1961h, p. 6).

Posteriormente, essa competição foi mesmo cancelada, o que causou grande decepção nos esportistas das províncias. Houve, todavia, os Jogos Desportivos Luso-Brasileiros, eventos que foram muito influenciados "pelas características dos relacionamentos estabelecidos entre Brasil e Portugal no âmbito da política externa, algo que foi marcado por um grande sentimentalismo e por uma leitura do passado entabulada a partir das ideias lusotropicalistas de Gilberto Freyre" (MELO, 2016).

A primeira edição foi realizada em Portugal, em 1960. A segunda, no Brasil, em 1963. A terceira, em 1966, de novo em Portugal, dessa vez não só na Europa, como também em várias cidades africanas, como Luanda e Lourenço Marques. Não houve competições na Guiné, o que aborreceu as lideranças esportivas locais, que reivindicavam que ao menos as provas de tênis fossem organizadas em Bissau. De toda forma, tratou-se claramente de mais uma tentativa de mobilizar o esporte para atender interesses metropolitanos.

Com o intuito de celebrar os laços do império português, para ser mais preciso da nação Portugal, eventualmente se anunciava a promoção de contendas entre equipes das províncias, como o Campeonato Ultramarino de Futebol, disputado em Luanda, em outubro de 1963. O representante da Guiné seria o Benfica de Bissau. Participariam também o Boavista de Praia, o Andorinhas de São Tomé, o Ferroviário de Luanda e o Sporting de Lourenco Marques, uma agremiação de cada colônia africana.

A logística demonstrou-se complicada, especialmente no tocante aos voos que levariam as equipes a Angola. Ao fim, a Guiné não foi representada, pois não se encontraram soluções

12 Para mais informações, ver Melo (2011a). 
para o problema de transporte, o mesmo que afastou também a participação dos cabo verdianos. Uma vez mais os conflitos dificultavam a concretização de iniciativas esportivas

A guerra colonial também interferiu na promoção de jogos e eventos comumente realizados, desde os anos 1940, entre equipes da Guiné e de colônias vizinhas, bem como de Cabo Verde. Deve-se ter em conta que, na década de 1950, o incentivo a essas iniciativas tinha relação com o fato de Portugal investir na participação em organismos de cooperação entre os países colonizadores (Conselho Científico da África ao Sul do Saara e Comissão de Cooperação Técnica na África ao Sul do Saara). Todavia:

[...] com o fortalecimento do movimento anticolonial e a africanização da CCTA, o país é afastado da organização, na sequência da $17^{\mathrm{a}}$ sessão, realizada em Abidjan, em 1962. Tratou-se de um rude golpe, sinal da célere transformação da relação de forças (CASTELO, 2014, p. 525).

A princípio, os encontros com equipes de Cabo Verde e de territórios ainda não independentes foram mantidos. Logo até essas ocasiões foram interrompidas. Foram afetadas mesmo as celebrações dos aniversários de clubes guineenses, durante anos festejados com eventos internacionais.

Em 1964, um dos mais tradicionais campeonatos na Guiné disputados, o Torneio Internacional de Páscoa, pela primeira vez não contou com equipes de fora da província. As lideranças esportivas até demonstravam compreender tal decisão - disse certa vez um cronista: "Os tempos mudaram. O momento atual não permite que continuemos a manter relações desportivas com esses vizinhos" (ARAUTO, 1967c, p. 16) -, mas conclamavam por alternativas para que os encontros não deixassem de existir.

Em 1965, o Torneio de Páscoa voltou a ter um convidado de fora da Guiné, ainda que não de fora do país, a Acadêmica de Coimbra, que retornava à província com o mesmo sucesso que lograra nos anos 1950. Frente às limitações de encontros com os vizinhos, passaram a ser mais frequentes as visitas de equipes da metrópole. Essas ocasiões ganharam um tom político ainda mais denotado, o discurso de que se tratava de uma iniciativa de integração do império, algo que sempre marcou esses encontros no decorrer da década.

Em abril de 1962, desembarcaram em Bissau, para realizar jogos em várias cidades, as seleções portuguesas de vôlei e handebol. Um cronista entusiasmado asseverou: "A cidade recebeu os atletas como que fossem seus: nados e criados aqui. Porque seus são. Do mesmo modo que os guineenses são do continente [...]. Os portugueses são da metrópole, das ilhas ou do ultramar" (ARAUTO, 1962a, p. 3). 
Tratou-se de um claro investimento do governo metropolitano, que inclusive mobilizou a força aérea para transportar os atletas, recebidos com grande festa pelas autoridades provinciais. $O$ tom de nacionalismo foi intenso. Reforçava-se a ideia de integridade do império quando a sua existência estava progressivamente em xeque.

A representação propagada foi a de que as seleções vieram tanto para colaborar com o desenvolvimento esportivo local quanto para trazer um "abraço" da metrópole, "nesta troca de sentimentos demonstrar ao mundo, mais uma vez, a razão de ser das províncias portuguesas de Além-Mar e a unidade e coesão de todos os territórios que constituem a Pátria Lusitana" (BOLETIM CULTURAL DA GUINÉ PORTUGUESA, 1962, p. 487). A fim de demonstrar ainda mais o compromisso com a integridade da nação, os metropolitanos fizeram donativos para a compra de um novo navio de guerra.

Ao afirmar que "Portugal está em Portugal", um cronista consagrou: "Em Bissau ou em Bafatá, em Farim ou em Bula, em Teixeira Pinto ou em Bissorã, irmanados no mesmo desejo e no mesmo brio - portugueses, pretos, mestiços e brancos - entregaram-se ao desenvolvimento desportivo local, alheios às contrariedades" (ARAUTO, 1962b, p. 3). A mensagem era de autodeterminação, à moda de resposta às pressões internacionais: $o$ suposto "jeito lusitano de ser", pouco compreendido pelos críticos, suplantaria qualquer dificuldade momentânea. Reiterava-se a política colonial tendo como mote as supostas contribuições à civilização do local.

Para o presidente da Federação Portuguesa de Handebol, tratava-se de uma "ação psicossocial". O termo bem define os novos alinhamentos da política colonial portuguesa. Era uma estratégia de aproximação e convencimento dos nativos a fim de impedir a propagação de pensamentos divergentes. ${ }^{13}$

Ideia semelhante se percebe na fala do chefe da delegação do Sporting de Lisboa, que se dirigiu à Guiné, em 1966, para tomar parte na comemoração do aniversário do Sporting de Bissau. Para ele, o propósito da visita era "honrar o desporto nacional e cooperar com o Governo nesta hora de preocupações para o país" (BOLETIM GERAL DO ULTRAMAR, 1966, p. 352). Até mesmo os Benficas de Bissau e Bolama festejaram a equipe lisboeta, deixando claro que a rivalidade que havia nos campos não era superior ao intuito de celebrar a nação portuguesa.

Mais do que exaltar os aspectos simbólicos, a delegação do Sporting trouxe de Lisboa um presente da Câmara Municipal, livros para serem distribuídos por escolas e bibliotecas. A agremiação metropolitana disputou jogos de futebol, handebol, futsal e basquete, ganhando todos a exceção de um empate com a seleção provincial da Guiné, o que foi comemorado como sinal de que o futebol local não estava tão mal. Essa leitura tinha em

13 Mais do que atuar no âmbito da propaganda, procurou-se, de fato, implementar algumas iniciativas para garantir maior respeito com os africanos. Para mais informações sobre a ação psicossocial, ver Bosslet (2014). 
conta a comum argumentação metropolitana acerca das contribuições para a civilização e desenvolvimento das províncias, algo que obviamente carecia de completa materialidade, explicitado inclusive pelas flagrantes desigualdades sociais.

Uma equipe guineense tivera antes um "bom desempenho", o que na ocasião teve desdobramentos. Em 1963, visitou a província outra conhecida agremiação da metrópole, o Lusitano, evento saudado como forma de lembrar que "esse cantinho do nosso ultramar, onde labutam milhares de portugueses, sente-se um pouco alheio ao que se passa na mãe Pátria" (ARAUTO, 1963c, p. 3). Tratou-se de uma ação direta do Conselho Provincial de Educação Física, que promoveu um torneio com um selecionado de Bissau, a seleção da Guiné e Os Balantas. Como de costume, muitas foram as exaltações à união da nação:

Das quentes planuras do Alentejo às terras chãs e ardentes da Guiné voa a comitiva do Lusitano de Évora para trazer o abraço dos desportistas da Metrópole às gentes do desporto guineense. Este é o propósito imediato da visita de tão distinto agrupamento desportivo (ARAUTO, 1963d, p. 4).

Como era usual, se valorizava o fato de o clube vir da metrópole para se irmanar com a Guiné, a sempre repetida ideia de que "Portugal está em Portugal", uma demonstração de que eram equivocadas as "acusações" da ONU e espúrios os intuitos dos "terroristas". A própria formação do Lusitano era mobilizada como exemplo da excepcionalidade do colonialismo português: havia jogadores europeus, um brasileiro, um de Cabo Verde e já houvera um guineense, Florentino da Silva Araújo, mais conhecido como Flora, que por lá atuara de 1952 a 1960.

A "portuguesidade" foi mesmo o mais enfatizado: "Os nossos irmãos de Mãe-Pátria [...] trouxeram-nos seu abraço, o abraço da solidariedade que une a Metrópole ao Ultramar Português" (ARAUTO, 1963f, p. 1). Por isso, celebrou um cronista: "Bem-vindo sejas, pois, símbolo de nossa terra. Bem-vinda sejas nobre embaixada lusitanista pelo muito que representas para esse povo humilde, mas bom, lhano e hospitaleiro" (ARAUTO, 1963d, p. 5).

Assim como ocorreu em outras ocasiões, a equipe ofereceu algo à província. Nesse caso, vieram juntos um árbitro e um técnico que ministraram palestras a fim de contribuir com o incremento do futebol local. No decorrer da visita, várias autoridades estiveram presentes nos jogos e recepções, os clubes do interior enviaram telegramas, funcionários públicos e do comércio foram liberados do trabalho para acompanhar a tudo. 
Dessa vez, todavia, não era das melhores a qualidade técnica do futebol dos metropolitanos. Mesmo ganhando do Benfica de Bissau, o Lusitano foi derrotado pela seleção de Bissau e empatou com o selecionado da Guiné. Os resultados foram encarados como um sinal do progresso da província, bem como de que Portugal vinha bem cumprindo sua missão civilizadora.

Mais ainda, o bom desempenho fortaleceu uma antiga reivindicação, a participação de uma equipe da Guiné na Taça de Portugal, alternativa já possível, desde 1957, para um clube de Angola e outro de Moçambique. Um cronista sugeriu que mesmo sendo modesta a província, com desenvolvimento esportivo limitado, havia guineenses jogando na metrópole, demonstrando o valor do futebol local (ARAUTO, 1961i, p. 1). O seu posicionamento tocou num ponto importante, o fato de que os da Guiné tentavam contrapor a ideia de que se tratava de uma colônia menos importante.

Em 1963, enquanto atuava pela admissão de uma agremiação da Guiné na Taça de Portugal, o Conselho Provincial de Educação Física planejou o envio de algumas equipes à metrópole, uma da capital (selecionado de Bissau) e outra do interior (Os Balantas). O argumento era estimular o melhor reconhecimento de um dos territórios portugueses fora da Europa, um elemento importante na manutenção do império.

Entre 22 de junho e 7 de agosto, deslocou-se para a metrópole a equipe dos Balantas para enfrentar o Lusitano. Na Guiné, saudou-se intensamente o envolvimento do governador e do Conselho Provincial nessa "conquista", interpretada como um reconhecimento de que a província era parte efetiva da nação, celebrando-se o caráter peculiar da colonização portuguesa:

\footnotetext{
Nessa embaixada desportiva que se desloca para Lisboa, há, além do contato desportivo, o que quer que seja de sugestivo, de simbólico a demonstrar a inequívoca posição da realidade portuguesa. Ontem os angolanos, moçambicanos, cabo-verdianos, macaenses, hoje os Balantas guineenses, amanhã os timorenses e doutras províncias simbolizam a única etnia que admitimos, cultivamos e veneramos - os portugueses (ARAUTO, 1963e, p. 2).
}

O Ministério do Ultramar (na época dirigido por Peixoto Correia ${ }^{14}$ ) e a Presidência da República atuaram intensamente para concretizar a viagem. A motivação anunciada era, em

14 Peixoto Correia teve uma forte ligação coma Guiné e com o esporte. Foi chefe de gabinete do governo de Sarmento Rodrigues, quando foi presidente do Conselho de Desportos. Dedicou grande atenção à prática esportiva quando foi governador de Cabo Verde (1957-1958) e da própria Guiné (1958-1962), bem como na condição de Ministro do Ultramar. 
nome da unidade nacional, oferecer aos africanos "os benefícios da civilização, das luzes da inteligência, do convívio social” (BOLETIM GERAL DO ULTRAMAR, 1963, p. 319).

Figura 2 - Recepção dos Balantas pelo Ministro do Ultramar

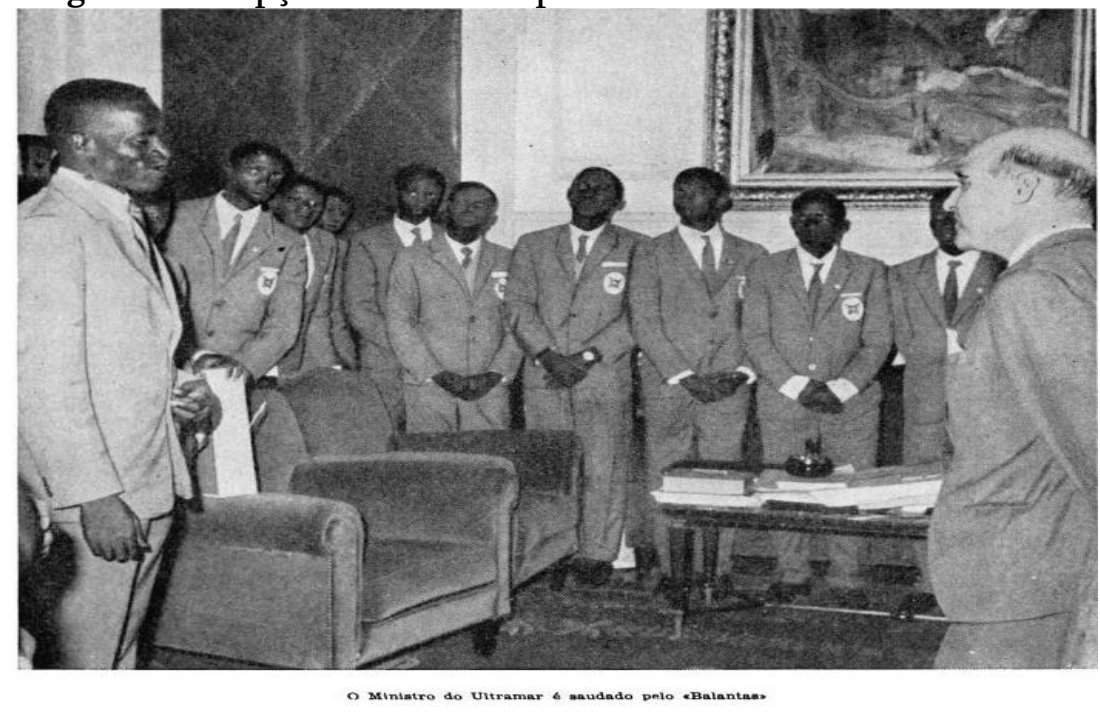

Fonte: Boletim Geral do Ultramar (1963, p. 319).

No ano seguinte, foi a vez da seleção provincial da Guiné ir a Lisboa, mas comemorada mesmo foi a tão reivindicada participação de uma equipe guineense na Taça de Portugal, na edição de 1964/1965, concessão considerada como "um louvável gesto de lusitanidade" da Federação Portuguesa de Futebol (BOLETIM CULTURAL DA GUINÉ PORTUGUESA, 1965a, p. $312)$.

A equipe campeã da Guiné, a UDIB, primeiro enfrentou a vencedora do campeonato de Cabo Verde, a Acadêmica de Mindelo, ocasião em que se acirraram antigas rivalidades entre as duas províncias, mas também discursivamente reafirmaram-se os tão idealizados laços de união do império: "Elos de uma corrente que se estende do Minho ao Timor, os desportistas portugueses das diversas colônias encontram-se irmanados no desejo fecundo de um alto ideal desportivo para quem as rivalidades não existem porque só conta o desejo de engrandecimento de seu ideal" (ARAUTO, 1965, p. 9).

Sagrando-se vencedora por saldo de gols (depois de uma vitória para cada equipe), a UDIB deslocou-se para a metrópole para disputar a fase seguinte com o Sporting Olhanense, uma partida em Olhão e outra em Lisboa, sendo derrotada em ambas. De fato, os clubes africanos nunca obtiveram sucesso na Taça de Portugal, sempre eliminados na primeira fase que jogaram. 
$\mathrm{Na}$ verdade, o envolvimento das equipes africanas era constantemente ameaçado em função da dificuldade de transporte. Além disso, as agremiações africanas por vezes se julgaram preteridas pelo fato de que os da metrópole nunca foram disputar seus jogos nas colônias ou alteravam regulamentos sem tê-las consultado. Um cronista chegou a perder a paciência: "Não somos benquistos no conceito do desporto mãe? Isto, já nós sabemos. Mas que haja sinceridade e que digam abertamente que não nos querem lá. Nós fazemos-lhes a vontade. Agora, jogar com 'pau de dois bicos' é que julgamos não valer a pena" (ARAUTO, 1968, p. 6).

Como de costume, a crítica dos cronistas mobilizava aquilo que o próprio governo propugnava. Se todos faziam parte de uma mesma nação, lhes parecia um equívoco não ter em conta de maneira mais convicta as demandas das províncias ultramarinas. Obviamente, nesse ponto de vista, não se tratava de reivindicação independentista, mas sim uma conclamação pela ratificação e operacionalização da ideia de império.

De toda forma, mesmo com todos os limites e críticas, em geral, a participação de equipes do ultramar na Taça de Portugal, tanto para os da metrópole quanto para os das províncias, por cronistas e dirigentes era celebrada como sinal de união e integridade do país, uma resposta aos que criticavam a nação Portugal.

\section{O esporte "Por uma Guiné melhor"}

Na década de 1960, a Guiné teve quatro governadores. Um deles foi o já citado Peixoto Correia (até 1962), substituído por Vasco Antônio Martínez Rodrigues (1962-1965), que tentou administrar a província ao mesmo tempo em que procurava dar conta do início da guerra colonial. O seu sucessor, Arnaldo Schulz (1965-1968), assumiu mais preparado para os combates, acumulando o cargo com o de Comandante-Chefe das Forças Armadas. Como suas estratégias não lograram sucesso, tornou-se governador Antônio Sebastião Ribeiro de Spínola (1968-1973).

Personagem importante da política portuguesa, militar reconhecido, Spínola, ao deixar a província, se envolveu ativamente com os movimentos de fim da ditadura e início da transição democrática (foi o primeiro presidente pós-Estado Novo). Como governador, destacou-se seu programa "Por uma Guiné Melhor". Enquanto ampliou o combate armado ao PAIGC, se aproximou das populações locais, dando-lhe mais protagonismo e melhorando suas condições de vida, intentando minar o fermento das forças de contestação. Para ele, era a única possibilidade de reverter a derrota eminente (WOOLLACOTT, 1983). 
Mais do que nunca se sentem os desdobramentos dos conflitos coloniais no âmbito esportivo. Spínola, desde o início e durante todo o seu período de governo, reiterou que dedicaria atenção ao tema, elencado como uma das estratégias para assegurar uma relação mais próxima com a população local.

Em cerimônia promovida para entrega da Taça da Guiné de 1969, considerou que nenhum administrador poderia deixar de ter em conta a importância da prática. Seu intuito era atingir a "grande massa do povo guineense que pretendemos valorizar física, intelectual e moralmente no quadro da consecução de uma vida melhor" (BOLETIM CULTURAL DA GUINÉ PORTUGUESA, 1969, p. 971). Vale observar que, no seu governo, foram ainda mais potencializadas as ações da Mocidade Portuguesa.

Da mesma forma, em várias regiões, as unidades militares utilizaram o esporte nos programas de ação psicossocial ${ }^{15}$, tanto naquilo que tangia ao incentivo da tropa quanto no tocante a ação com a população, iniciativas que misturavam "a psicologia, a propaganda e a animação cultural" (ALEXANDRE, 2015, p. 103).

Convencidos desse interesse, alinhados à política metropolitana, os cronistas assumiram o compromisso de incentivar tudo o que dizia respeito ao tema. Não se tratou, todavia, de um apoio incondicional. Procuraram também apontar os principais problemas de estruturação do esporte, reconhecendo que na província enfrentava dificuldades diversas. Um jornalista assim declarou seu intuito:

\begin{abstract}
Abordará assuntos, tocará casos, apontará defeitos, exaltará virtudes. Tudo dentro da melhor intenção: algo fazer para o bem do desporto local. Este desporto que, na presente conjuntura, está atravessando época de mau caminho e de mau signo. Será tempestade em copo de água (NOTÍCIAS DA GUINÉ, 1968a, p. 11).
\end{abstract}

No seu modo de entender se teria chegado a um estágio de decadência também por falta de compromisso dos próprios agentes do campo: "O desporto local está no caos. [...]. Concluise, de forma categoria, que muitos o que faziam e fazem é retalhar, esfrangalhar, o já de si enfraquecido desporto guineense" (NOTÍCIAS DA GUINÉ, 1968b, p. 7). Os cronistas depositavam suas esperanças na mudança de postura da nova administração provincial:

15 Para mais informações sobre a ação psicossocial na Guiné, ver Alexandre (2015), com especial interesse para os relatos de Otelo Saraiva de Carvalho e Carlos Miguel, líderes das iniciativas, 
Em tempo oportuno salientamos que reinava por aqui um descontrole muito grande pela parte de certos dirigentes e de certos técnicos. Faziam-se afirmações ofensivas, tomavam-se atitudes pouco percebíveis... [...]. Felizmente parece despontar agora uma vontade firme e decisiva, por parte das instâncias superiores, em remediarem todo o mal que se fez, em procurarem escolher pessoas capazes de dirigirem a barca a bom termo (NOTÍCIAS DA GUINÉ, 1968c, p. 5).

Havia muita apreensão com o fato de que avançavam alguns aspectos da vida citadina em Bissau e isso não se refletia nas instalações esportivas. A única exceção foi o anúncio da construção de uma nova sede para a UDIB. Em cerimônia prestigiada pelo governador, autoridades provinciais e representantes de todos os clubes, marcada por demonstrações de civismo, não se conseguiu deixar de fazer referências à "era vertiginosa em que vivemos nos nossos dias, em que por vezes não há lugar para recordações” (NOTÍCIAS DA GUINÉ, 1969a, p. 7).

De toda forma, havia um clima de otimismo, inclusive no que tange às campanhas militares, o que ajudava a justificar o investimento na construção de uma sede que, "pelas linhas arquitetônica modernas", ajudaria a embelezar "a principal artéria da cidade de Bissau" (NOTÍCIAS DA GUINÉ, 1969a, p. 7).

A despeito das intenções anunciadas, não era fácil recuperar a movimentação esportiva que houvera antes, especialmente nas modalidades que não o futebol. Havia ainda alguns campeonatos bem estruturados, mas reduzira-se a frequência e continuidade das iniciativas.

Especialmente em algumas cidades sentia-se claramente o efeito dos conflitos. Aos cronistas muito incomodava o fato de que o esporte no "interior da província, que tão belas páginas escreveu no conceito desportivo dessa terra, [...], encontra-se em ponto morto" (NOTÍCIAS DA GUINÉ, 1969b, p. 5). No campeonato de futebol de 1968, somente uma equipe de fora da capital participou, o Nuno Tristão de Bula. ${ }^{16}$

De toda forma, o velho esporte bretão ainda mantinha algo de seu vigor, até mesmo com o incremento de um campeonato popular, com times menos estruturados, ${ }^{17}$ realizado no período do defeso, disputa que empolgou muito a capital e revelou bons jogadores, alguns "contratados" pelas agremiações. Entre esses grupos, chegou-se a constituir um clube que participou das contendas provinciais, o Ajuda Sport.

16 Da capital, tomaram parte as três agremiações mais tradicionais - UDIB, Benfica e Sporting, duas que já tinhamalgum tempo de vida (o Tênis Clube e a Ultramarina) e uma mais recente (Sacor). Outro clube mais jovem que participou de algumas contendas e ocupou espaço importante em Bissau foi o Ancar.

17 Era muito grande o número de equipes populares que jogavam nas ruas e campos das cidades. Esse é um tema que merece ser investigado em ocasiões futuras. 
Ainda assim, definitivamente se extinguiu a realização de jogos com equipes de fora da Guiné. Em 1968, o Sporting de Lisboa informou que não poderia de novo visitar a província. Foi convidada, então, uma agremiação de Angola, o Atlético Sport Aviação, que, contudo, ao fim não chegou a viajar para Bissau. O Torneio de Páscoa, que já não era internacional, foi cancelado.

Esse contexto se refletiu também na participação da equipe da Guiné na Taça de Portugal. Na edição de 1969, sequer houve a disputa inicial com a agremiação de Cabo Verde, que desistiu de tomar parte na contenda. Assim, a UDIB automaticamente se classificou para o jogo em Lisboa, com o Sporting metropolitano.

Os cronistas não alimentaram muitas ilusões com essa partida. Para um deles, "o momento atual do futebol guineense está longe de permitir sequer um raio de esperança ao nosso representante" (NOTÍCIAS DA GUINÉ, 1969c, p. 7). Para além da notória superioridade da equipe metropolitana, reiterava-se a decadência pela qual passavam a UDIB e o futebol da província como um todo. O máximo que se esperava é que o clube de Bissau fosse para Lisboa "de sorriso nos lábios, sem aspirações que não sejam as de marcar, na terra da Mãe Pátria, uma posição de relevo no âmbito da disciplina e da correção" (NOTÍCIAS DA GUINÉ, 1969d, p. 13).

Frente ao quadro, os cronistas, com saudosismo, diagnosticavam: "Retrocedamos a alguns anos...Poucos! [...]. Como era agradável ver-se o entusiasmo como que em toda província se vivia o desporto e o desporto era vivido!” (NOTÍCIAS DA GUINÉ, 1968d, p. 7). Essa sensação de saudade ajuda a entender que, em 1969, tenham sido publicadas várias matérias sobre os mais destacados jogadores da história do futebol guineense. Todos foram elogiados por sua personalidade positiva, supostamente resultado da pujança da terra, colonizada de forma digna por Portugal. Foram exaltados por dignificar "o desporto desta nossa Guiné, afirmando, que nestas paragens tão portuguesas, o futebol também não é uma palavra vã" (NOTÍCIAS DA GUINÉ, 1969e, p. 9).

O cenário que se impunha na Guiné fazia os colonos sentirem falta de um tempo que não mais voltaria. Em 1971, ainda houve uma melhora relativa no quadro da movimentação esportiva. Percebe-se pelo menos um maior número de iniciativas de distintas modalidades, inclusive de algumas que há algum tempo não se praticava na colônia, como o basquetebol. Até mesmo um rally Bissau-Mansoa foi promovido, encarado como uma expressão de que o governo tinha controle total sobre o território, o que não era verdade naquela ocasião - o PAIGC já conquistara vastas extensões de terra.

Essa retomada não passou de um suspiro. Os conflitos tornaram-se definitivamente a ordem do dia. A luta pela independência não seria freada. Em poucos anos mudanças profundas seriam promovidas na Guiné dirigida pelas lideranças do PAIGC. 


\section{Na zona de conflito}

Se as guerras coloniais foram determinantes para que o Estado Novo chegasse ao fim, ainda mais o foi a que ocorreu na Guiné. Por diversos motivos, esse conflito se delineou como um desastre completo para Portugal, do ponto de vista diplomático, militar e político: as características do território, o apoio de alguns países recém-independentes nas fronteiras, a força das ideias de Amílcar Cabral, a organização crescente do PAIGC (WOOLLACOTT, 1983).

As iniciativas do Partido foram logrando sucesso tanto no cenário internacional, com o aumento de apoios políticos e militares, quanto internamente, com a conquista de territórios nos quais se procurou promover a melhoria de vida da população. Em 1973, o PAIGC se sentiu forte o suficiente para unilateralmente proclamar a independência, logo reconhecida pela ONU e por muitos Estados (PINTO, 1999).18

A essa altura, era crescente a insatisfação das tropas portuguesas com a situação, inclusive com o aumento de nativos ocupando postos de comando. Entre algumas lideranças militares começou a se semear a ideia de que os revolucionários guineenses não eram seus verdadeiros inimigos, mas sim certos setores da política metropolitana (WOOLLACOTT, 1983).

Nesse quadro, reduziu-se o ímpeto de combate das tropas portuguesas, progressivamente derrotadas, inclusive, em virtude da melhoria do armamento das forças do PAIGC, especialmente quando se conseguiu mísseis antiaéreos mais eficientes (os soviéticos Strella). Nos anos finais do colonialismo, o exército lusitano ficou acuado frente às investidas dos revolucionários.

Não surpreende que, na Guiné, tenham sido intensos os desdobramentos da Revolução dos Cravos. À revelia do poder metropolitano, que passou por um processo turbulento de transição, militares portugueses ligados ao $\mathrm{MFA}^{19}$ assumiram o poder local e, demonstrando até mesmo simpatia por algumas causas do PAIGC, encaminharam o reconhecimento da independência, pressionando por mudanças nos rumos da nação.

$18 \mathrm{Na}$ verdade, no ano anterior foram realizadas eleições nas zonas libertadas; a independência foi uma decisão da eleita Assembleia Nacional. Portugal só a reconheceu em 1974, no desdobramento da Revolução dos Cravos.

19 O Movimento das Forças Armadas, liderado e integrado majoritariamente por oficiais de nível intermediário (notadamente capitães), foi o principal responsável por desencadear a Revolução dos Cravos, sendo tambémum dos mais ativos no momento de transição democrática, emgeral adotando ideias mais progressistas. Para mais informações, ver Varela (2012). 
Nos estertores do colonialismo, depois do 25 de abril, houve mesmo contatos entre as forças metropolitanas e o PAIGC: "Trocavam-se opiniões acerca da guerra e das negociações enquanto se bebiam uns copos e, à medida que a confiança e as amizades cresciam, os inimigos de ontem convidavam-se mutuamente para jantares e convívios intermináveis" (WOOLLACOTT, 1983, p. 1148). Depois de tanta crueldade, segundo o autor, "O processo de confraternização na Guiné foi de fato extraordinário e sem paralelo na história da descolonização ocidental em África".

É provável que haja algum exagero nessas considerações, que as coisas não tenham ocorrido exatamente dessa forma, pelo menos não generalizadamente, inclusive porque não se desarmam rapidamente os impulsos de guerra. Devemos tomar cuidado para não reiterar as teses que exaltam a suposta cordialidade do colonialismo português. Não se deve, todavia, desprezar a hipótese de que tenha havido alguma forma de relação entre os grupos, o que também se manifestou no âmbito esportivo.

Figura 3 - Confraternização de guerrilheiros do PAIGC, população local e militares portugueses de Cansissé; junho de 1974

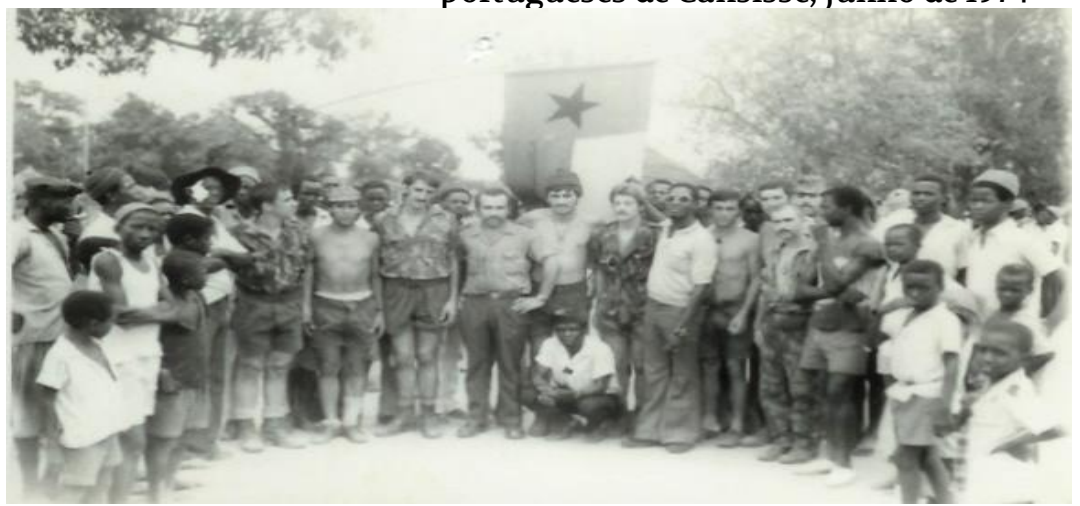

Fonte: Marques (2005).

Como vimos, enquanto se acirrava a guerra colonial, ainda que fossem sentidos impactos dos conflitos, se tentou manter ativa a vida esportiva. Há outra faceta do fenômeno que merece um olhar atento: a sua prática em plena zona de combates, por parte tanto das forças armadas portuguesas quanto do PAIGC. Não encontramos muitas fontes para prospectar o tema ${ }^{20}$, mas o que conseguimos nos permite ter uma noção de que o esporte ocupou um papel de relativa importância naquele âmbito.

Até mesmo por ocupar importância nas estratégias de mobilização e na própria trajetória de Cabral e outros líderes (MELO, 2011a), não chega a surpreender a valorização das atividades físicas nas iniciativas do PAIGC. Na Escola-Piloto de Conacri, uma das mais 
importantes ações ligadas às propostas educacionais do Partido, ${ }^{21}$ criada para atender jovens e crianças feridas ou que por razões do conflito tiveram que ser retiradas da Guiné, a educação física era uma matéria obrigatória. ${ }^{22}$ Vale destacar que a disciplina estava entre os cursos superiores que se gestionou no exterior para enviar militantes tendo em vista potencializar o alcance dos intuitos partidários (FUNDAÇÃO MÁRIO SOARES, 1965b).

Os dias de aula se iniciavam com sessões de ginástica e esporte (futebol, voleibol, pingpong, tiro e alguns jogos infantis). Para os líderes do PAIGC, tratava-se de garantir o que consideravam um direito: os cuidados com a saúde e higiene, bem como o acesso a uma faceta da cultura.

Nas outras escolas do PAIGC, a educação física não integrava as disciplinas oferecidas, mas desempenhava uma importante função:

As necessidades da nossa luta e as tarefas de organização que se levantam nas zonas libertadas exigem que a escola se ligue intimamente à luta e à vida. Além duma formação política, os nossos alunos são submetidos a uma preparação física e militar. A todo momento é preciso estar-se preparado para fazer face ao inimigo e aguentar a violência dos seus bombardeamentos. (FUNDAÇÃO MÁRIO SOARES, 1965b).

Em outras esferas, as atividades físicas eram também valorizadas. A ginástica era lecionada no Lar dos Combatentes, ${ }^{23}$ que acolhia os que deixavam a Guiné e iam para Conacri, para preparar-se para participar dos conflitos armados. ${ }^{24}$ A prática esteve presente em outras instâncias de formação militar. Por exemplo, no programa de treinamento oferecido em um campo no Marrocos, em 1962, a educação física recebia grande atenção, em conjunto com outras noções necessárias à guerra, como tiro e armamento. ${ }^{25}$

O mesmo se identifica no Programa para a Preparação de Soldados das Forças Armadas Revolucionárias do Povo (FARP), ${ }^{26}$ lançado, em 1968, pela Escola de Formação de Combatentes, que tinha como um de seus intuitos "Preparar os nossos combatentes

21 A educação foi uma das prioridades do PAIGC. Em1965, já havia 50 escolas nas zonas liberadas. Para mais informações, ver: Fundação Mário Soares (2015).

22 Imagens dessas aulas estão disponíveis em: Fundação Mário Soares (1965a, 1965b).

23 Uma imagem dessas aulas está disponível em Fundação Mário Soares (1963a).

24 Uma documentação interessante sobre o Larpode ser encontrada em: Fundação Mário Soares. Documentos Amílcar Cabral. Pasta: 07062.034.045. Documento incluído no dossier intitulado Manuscritos de Amílcar Cabral. (FUNDAÇÃO MÁRIO SOARES, 2015c).

25 Programa da formação técnica e militar dos estagiários do PAIGC em Marrocos. (FUNDAÇÃO MÁRIO SOARES, 1962). 26 As FARP foram um avanço na organização militar do PAIGC, potencializando suas ações armadas. 
fisicamente, de forma a que possam levar a cabo as ações militares e as marchas com o êxito. [...] Para conseguir este objetivo deve-se treinar-se o pessoal em ginástica, campos de obstáculos e em combates de corpo a corpo" (FUNDAÇÃO MÁRIO SOARES, 1968).

O PAIGC manteve também equipes de futebol nas zonas liberadas, para animar a população, bem como seus militantes e membros das forças militares. ${ }^{27}$ No Lar dos Combatentes, por exemplo, em todos os fins de tarde, depois de um árduo dia de formação, havia partidas do velho esporte bretão (AMADO, 2011).

Em alguns documentos encontramos referências tangenciais, mas importantes, à prática do esporte. Vejamos a carta de Nino Vieira ${ }^{28}$ para Luís Cabral, ${ }^{29}$ de 1963 ou 1964, solicitando alguns materiais. Entre outros, pede: "É favor enviar-nos também uma bola de futebol" (FUNDAÇÃO MÁRIO SOARES, 2015a). O mesmo se vê em outra correspondência dos dois, na qual o primeiro informava sobre o trânsito de combatentes, tratava de uma questão de comércio relevante para a guerra e solicitava: "Agradeço-lhe mandar-me oferecer bolas de futebol". (FUNDAÇÃO MÁRIO SOARES, 2015b).

Já Lourenço Gomes (membro do bureau político do PAIGC), em carta a Luís Cabral, datada de 4 de dezembro de 1964, em meio a outros assuntos relativos à guerra, lembra que pedira a Aristides Pereira ${ }^{30}$ algumas "bolas de futebol, mas daquelas que têm o birro para dentro, isto é, com as câmaras de ar fixas, pois aquelas que trouxe não valem nada". (FUNDAÇÃO MÁRIO SOARES, 1964). Solicita que sejam enviadas ao menos quatro, se possível até mais, "pois no interior de nosso país e em quase todas as bases os nossos jovens gostam de jogar futebol".

No que tange aos militares portugueses, já vimos que alguns integraram clubes e participaram de competições provinciais. Todavia, houve outras formas de envolvimento com o esporte. O ex-furriel enfermeiro Armando Pires recorda que, em seu quartel em Bula, praticou diferentes modalidades, entre as quais o futebol, o voleibol e a natação. Foi beneficiado pelo fato de que em sua companhia havia muitos adeptos do esporte. (PIRES, 2014).

Até mesmo por haver muitos bons jogadores, lembra que nem sempre foi tranquila a formação de equipes no âmbito de sua corporação; o excesso de competitividade por vezes gerou certa cizânia. Não podemos dizer que isso chegou a macular o intuito de fortalecer o espírito de corpo, apenas chamar a atenção para o fato de que a dinâmica esportiva nem sempre, ou muitas vezes, segue aquilo que idealmente é formulado.

\footnotetext{
27 Imagens dessas ocasiões estão disponíveis em Fundação Mário Soares (1960, 1963c).

28 Um dos líderes do PAIGC, futuro presidente da Guiné Bissau.

29 Primeiro presidente da Guiné Bissau independente.

30 Primeiro presidente de Cabo Verde independente.
} 
Antônio Graça de Abreu (2007) narra uma dessas situações de conflito, ocorrida em seu quartel em Canchungo, em fevereiro de 1973. Uma briga em um jogo de futebol, disputado entre equipes de militares brancos e negros (muitos foram os guineenses que lutaram do lado dos portugueses), levou à prisão alguns do time dos nativos, o que desencadeou um motim, a muito custo controlado. O episódio refletiu o aumento das tensões raciais nos momentos finais da guerra colonial, sentidas mesmo dentro das forças portuguesas.

Como Abreu, Manuel Vaz, que serviu em Gadamael Porto, lembra dos momentos esportivos como um hábito menos normatizado do que se apresenta no relato de Armando Pires:

Mas nem só de descargas e colunas de reabastecimento, de operações ou abrigos se vivia [...]. No coração e na mente da rapaziada muito havia para viver ou não fosse aquela a idade dos sonhos, dos projetos... e tudo contido no interior da paliçada, entrincheirado nos abrigos, limitado pelo arame farpado! (VAZ, 2012).

Os jogos eram mais improvisados. Não havia muitas equipes envolvidas, tampouco torneios mais estruturados, não sendo, por isso, ocasiões menos esperadas:

Mas havia sempre quem guardasse um calendário e religiosamente cortasse os dias que passavam. Por isso, dava conta dos domingos, feriados, dias santos e avisava que era dia de jogar à bola! E se nada fundamental fazia parte da "ordem do dia", pois porque não? Praticar desporto também é importante para desanuviar o espírito.

Jorge Araújo, em informe cheio de imagens de jogos de futebol, lembra que esses momentos de festa extravasavam os campos: "Concluído cada jogo da bola, o processo de socialização mudava de terreno de prática, sendo transferido para o bar, onde os gols tinham outro sabor, e as conservas e outros alimentos eram digeridos, igualmente com grande prazer e satisfação" (ARAÚJO, 2013). O esporte, sem dúvida, em muitas situações ajudou mesmo a fortalecer laços de amizade na tropa.

O velho esporte bretão, tão importante nos quartéis, também esteve contemplado nas iniciativas do Movimento Nacional Feminino, que tentava apoiar os militares portugueses 
de maneiras diversas, inclusive com a oferta de produtos diversos, tais como cigarros, material de limpeza pessoal, livros, aerogramas para comunicação com familiares, entre outros. ${ }^{31}$ Bolas e uniformes de futebol faziam parte da sua lista de distribuição (ALMEIDA, 2013).

A prática do futebol também se observou nos momentos finais da guerra colonial. Nos encontros que houve entre as forças armadas portuguesas e do PAIGC, no pós 25 de abril, em algumas regiões foram disputadas partidas entre os antigos inimigos (WOOLLACOTT, 1983).

Na verdade, em plena guerra, o velho esporte bretão deixou imagens curiosas, indicadores das contradições que cercaram o conflito. Luís Cabral (1984) sugere, de forma obviamente bem atenuada, mas possivelmente não caluniosa, ${ }^{32}$ que:

Estiveram detidos em Conakry mais de vinte militares europeus que tinham alimentação especial, com direito a irem à praia, que não ficava longe, uma vez por semana. No pátio do prédio transformado em prisão, havia um campo para desporto, onde faziam exercícios físicos. Muitos aprenderam a ler e a escrever e no fim já eram eles próprios a escreverem às famílias, o que lhes era facultado com a colaboração da Cruz Vermelha Senegalesa e a Cruz Vermelha Internacional (CABRAL, 1984, p. 392).

No acervo da Fundação Mário Soares, de fato, é possível encontrar fotos de jogos de futebol disputados entre prisioneiros portugueses e membros do PAIGC. (FUNDAÇÃo MÁRIO SOARES, 1963b). É verdade que isso pode não ter passado de uma ou outra ocasião. De toda forma, vale o registro da possibilidade de que, de alguma forma, o futebol tenha sido interesse compartilhado.

É possível inferir que os dois grupos, forças armadas de Portugal e do PAIGC, lograram algum sucesso na mobilização do esporte. A propósito, se observarmos bem, a despeito dos intuitos divergentes, as ideias e imagens nos ajudam a entender que ambos usaram a prática com certas semelhanças. De um lado, era uma forma de ajudar a suportar a dura vida da guerra, uma diversão cotidiana com a qual se envolviam mais intensamente os que já a apreciavam (como era, na verdade, para o grande conjunto da população). De outro lado,

31 Criado por mulheres portuguesas, ligadas à burguesia e apoiadoras do regime - como uma das mais conhecidas líderes, Cecília Supico Pinto -, contou com apoio dos órgãos do Estado Novo.

32 Não cabe neste estudo aprofundar esse tema, mas há de ambos os lados relatos de violência extremada com prisioneiros de guerra. Um bom relato do assunto pode ser visto em: (PRISIONEIROS..., 2015). 
junto com a ginástica, era concebido como ferramenta para a preparação do combate, para desenvolver espírito de grupo, aptidão física, controle e disciplina.

\section{Fontes Documentais}

Arauto, 13 jul. 1961a.

Arauto, 29 jan. 1961b.

Arauto, 19 set. 1961c.

Arauto, 23 set. 1961d.

Arauto, 30 abr. 1961e.

Arauto, 1 dez. 1961f.

Arauto, 25 jul. 1961g.

Arauto, 11 maio 1961h.

Arauto, 28 jul. $1961 i$.

Arauto, 19 abr. 1962a.

Arauto, 28 abr. 1962b.

Arauto, 12 fev. 1963a.

Arauto, 17 maio 1963b.

Arauto, 26 mar. 1963c.

Arauto, 7 abr. 1963d.

Arauto, 22 jun. 1963e.

Arauto, 10 abr. $1963 f$

Arauto, 18 abr. 1965. 
Arauto, 1 abr. 1967a.

Arauto, 8 nov. 1967b.

Arauto, 1 jan. 1967c.

Arauto, 10 jan. 1968.

Boletim Cultural da Guiné Portuguesa, v. 17, n. 67, 1962.

Boletim Cultural da Guiné Portuguesa, v. 20, n. 79, 1965.

Boletim Cultural da Guiné Portuguesa, v. 24, n. 96, 1969.

Boletim Geral do Ultramar, v. 39, n. 456-457, 1963.

Boletim Geral do Ultramar, v. 42, n. 491, maio 1966.

Notícias da Guiné, 21 abr. 1968a.

Notícias da Guiné, 30 jun. 1968b.

Notícias da Guiné, 28 abr. 1968c.

Notícias da Guiné, 15 dez.1968d.

Notícias da Guiné, 2 fev. 1969a.

Notícias da Guiné, 20 jul. 1969b.

Notícias da Guiné, 30 mar. 1969c.

Notícias da Guiné, 11 maio 1969d.

Notícias da Guiné, 15 jun. 1969e.

\section{Referências}

ABREU, A. G. Diário da Guiné: lama, sangue e água pura. Lisboa: Guerra e Paz, 2007.

ALEXANDRE, D. O outro lado da guerra colonial. Lisboa: A Esfera dos Livros, 2015.

ALMEIDA, A. R. A. Guiné mal amada: o inferno da guerra. Porto: Fronteira do Caos, 2013. 
AMADO, L. Guerra colonial \& guerra de libertação nacional (1950 - 1974): o caso da GuinéBissau. Lisboa: Instituto Português de Apoio ao Desenvolvimento, 2011.

ARAÚJO, J. O "jogo da bola" nos intervalos da guerra de guerrilha. 2013. Disponível em: $<$ https://docs.google.com/file/d/0B16q2O9XZg47VVZVVkZObFhHRWM/ edit?pli=1>. Acesso em: 5 set. 2016.

BALE, J.; CRONIN, M. (Ed.). Sport and postcolonialism. Nova Iorque: Berg, 2003.

BOSSLET, J. C. F. A cidade e a guerra: relações de poder e subversão em São Paulo de Assunção de Luanda (1961-1975). 2014. Dissertação (Mestrado em História) - Universidade Federal Fluminense, Niterói, 2014.

CABRAL, L. Crónica da libertação. Lisboa: Ed. O Jornal, 1984.

CARDOSO, C. A ideologia e a prática da colonização portuguesa na Guiné e o seu impacto na estrutura social - 1926-1973. Soronda, Bissau, n. 14, p. 29-61, 1992.

CARVALHO, N. T. De campo a campo: conversas com o comandante Bobo Keita. Porto, 2011.

CASTELO, C. "Novos Brasis" em África: desenvolvimento e colonialismo português tardio. Varia História, Belo Horizonte, v. 30, n. 53, p. 507-532, maio/ago. 2014.

CASTELO, C. O modo português de estar no mundo: o luso-tropicalismo e a ideologia colonial portuguesa, 1933-1961. Porto: Afrontamento, 1998.

FUNDAÇÃO MÁRIO SOARES. Aula de ginástica na Escola-Piloto do PAIGC em Conakry. 1965a. Disponível em: <http://casacomum.org/cc/visualizador?pasta= 05222.000.147>. Acesso em: 4 set. 2015.

FUNDAÇÃO MÁRIO SOARES. Combatentes do PAIGC durante exercício de ginástica. 1963a. Disponível em: $<$ http://casacomum.org/cc/visualizador?pasta $=05222.000 .236>$. Acesso em: 5 set. 2015.

FUNDAÇÃO MÁRIO SOARES. Convívio entre prisioneiros portugueses e elementos do PAIGC no termo de um desafio de futebol. 1963b. Disponível em: $<$ http://casa comum.org/cc/visualizador?pasta=05222.000.410 >. Acesso em: 5 set. 2015.

FUNDAÇÃO MÁRIO SOARES. Correspondência. Disponível em: $<$ http://casacomum.org/cc/visualizador?pasta=04613.065.096\#!1>. Acesso em: 5 set. 2015a.

FUNDAÇÃO MÁRIO SOARES. Correspondência. Disponível em: $<$ http://casacomum.org/cc/visualizador?pasta=04613.065.118\#!11>. Acesso em: 5 set. 2015b 
FUNDAÇÃO MÁRIO SOARES. Correspondência. 1964. Disponível em: $<$ http://casacomum.org/cc/visualizador?pasta=07071.123.065\#!1>. Acesso em: 4 set. 2015.

FUNDAÇÃO MÁRIO SOARES. Equipa de futebol constituída por jovens militares do PAIGC. 1960. Disponível em: $<$ http://casacomum.org/cc/visualizador?pasta $=05222.000 .086>$. Acesso em: 5 set. 2015.

FUNDAÇÃO MÁRIO SOARES. Escola para a formação de combatentes. 1968. Disponível em: $<$ http://casacomum.org/cc/visualizador?pasta=04602.047\#!4>. Acesso em: 5 set. 2015.

FUNDAÇÃO MÁRIO SOARES. Jogo de futebol. 1963c. Disponível em: $<$ http://casa comum.org/cc/visualizador?pasta=05360.000.123>. Acesso em: 4 set. 2015.

FUNDAÇÇÃO MÁRIO SOARES. Lar dos combatentes de Conakry: instrução política e militar. Disponível em: $<$ http://casacomum.org/cc/visualizador?pasta $=07062.034 .045>$. Acesso em: 5 set. 2015c.

FUNDAÇÃO MÁRIO SOARES. PAIGC: a nossa luta pela educação das massas e pela formação de quadros. 1965b. Disponível em: <http://casacomum.org/cc/visualizador? pasta $=04340.003 .009 \# ! 1>$. Acesso em: 4 set. 2015.

FUNDAÇÃO MÁRIO SOARES. Programa da formação técnica e militar dos estagiários do PAIGC em Marrocos. 1962. Disponível em: <http://casacomum.org/ cc/visualizador?pasta=07068.098.016\#!1>. Acesso em: 7 set. 2015.

MARQUES, Américo. Guiné 63/74 - P866: de Cansissé e a fonte dos Fulas ao Baixo Mondego ou como o mundo é pequeno (Idálio Reis). 2005. Disponível em: $<$ https://blogueforanadaeva otres.blogspot.com.br/2006/06/guin-6374-p866-de-cansiss-efonte-dos.html>. Acesso em: 15 dez. 2016.

MELO, V. A. (Des)mobilização para a luta: o esporte como estratégia nos conflitos da Guiné portuguesa (décadas de 50 e 60 do séc. XX). Métis: História \& Cultura, Caxias do Sul, v. 10, n. 19, p. 215-235, jan./jun. 2011a.

MELO, V. A. Jogos de identidade: o esporte em Cabo Verde. Rio de Janeiro: Apicuri, 2011b.

MELO, V. A. O esporte na política colonial portuguesa: as iniciativas de Sarmento Rodrigues na Guiné (1945-1949). Revista Brasileira de História, São Paulo, v. 34, n. 68, p. 175-192, 2014.

MELO, V. A. Os jogos desportivos Luso-Brasileiros e os Congressos Luso-Brasileiros de educação física no âmbito das relações internacionais Brasil-Portugal (década de 1960). Revista Brasileira de Ciências do Esporte, Porto Alegre, v. 38, n. 1, p. 34-41, 2016. 
MELO, V. A.; BITTENCOURT, M. O esporte na política colonial portuguesa: o Boletim Geral do Ultramar. Tempo, Niterói, v. 19, n. 34, p. 69-80, 2013.

PIMENTA, F. T. Portugal e o século XX: Estado-Império e descolonização (1890-1975). Lisboa: Afrontamento, 2010.

PIMENTEL, I. F. Mocidade Portuguesa Feminina. Lisboa: A Esfera dos Livros, 2007.

PINTO, A. C. Portugal e a resistência à descolonização. In: BETHENCOURT, F.; CHAUDHURI, K. (Org.). História da expansão portuguesa: volume 5: último império e recentramento (19301998). Lisboa: Círculo de Leitores, 1999. p. 51-64.

PIRES, A. Guiné 63/74 - P13749: Furriel enfermeiro, ribatejano e fadista (Armando Pires) (15): e agora, 0 desporto. 2014. Disponível em: $<$ https://blogueforanadaevaotres.blogspot.com.br/2014/10/guine-6374-p13749-furrielenfermeiro.html>. Acesso em: 5 set. 2015.

PRISIONEIROS. Guerra Colonial. Disponível em: <http://www.guerracolonial.org/ index.php?content=421>. Acesso em: 4 set. 2015.

SILVA, A. E. D. Guiné-Bissau: a causa do nacionalismo e a fundação do PAIGC. Cadernos de Estudos Africanos, Lisboa, n. 9-10, p. 141-167, 2006.

VARELA, R. "Um, dois, três MFA...": o movimento das forças armadas na revolução dos cra vos - do prestígio à crise. Revista Brasileira de História, São Paulo, v. 32, n. 63, p. 403-425, 2012.

VAZ, M. Guiné 63/74 - P9435: memórias da CCAÇ 798 (Manuel Vaz) (6): uma perspectiva a partir de Gadamael Porto - 65/67 - VI Parte - momentos de descompressão. 2012. Disponível em: <http://blogueforanadaevaotres.blogspot.com.br/2012/02/guine-6374-p9435-memoriasda-ccac-798.html>. Acesso em: 5 set. 2015.

VIEIRA, J. Mocidade Portuguesa. Lisboa: A Esfera dos Livros, 2008.

WOOLLACOTT, J. A luta pela libertação nacional na Guiné-Bissau e a revolução em Portugal. Análise Social, Lisboa, v. 19, n. 77-79, p. 1131-1155, 1983.

Recebido em 20.09.2015

Aprovado em 01.09.2016 